\title{
Interaction between the physical forms of starter and forage source on growth performance and blood metabolites of Holstein dairy calves
}

\author{
H. Omidi-Mirzaei, ${ }^{*}$ A. Azarfar, ${ }^{* 1}$ A. Kiani, ${ }^{*}$ M. Mirzaei, $\dagger$ and M. H. Ghaffari ${ }^{2}$ \\ *Department of Animal Science, Faculty of Agriculture, Lorestan University, PO Box 465, Khorramabad 44316-68151, Iran \\ †Department of Animal Science, Faculty of Agriculture and Natural Resources, Arak University, Arak 38156-88349, Iran \\ fDepartment of Agricultural, Food and Nutritional Science, University of Alberta, Edmonton, Canada, T6G 2P5
}

\begin{abstract}
The objective of this study was to investigate the effects of the physical forms of starter and forage sources on feed intake, growth performance, rumen $\mathrm{pH}$, and blood metabolites of dairy calves. Forty male Holstein calves (41.3 $\pm 3.5 \mathrm{~kg}$ of body weight) were used (n $=10$ calves per treatment) in a $2 \times 2$ factorial arrangement of treatments with the factors being physical forms of starter (coarse mash and texturized) and forage source [alfalfa hay (AH) and wheat straw (WS)]. Individually housed calves were randomly assigned to 1 of the 4 dietary treatments, including (1) coarsely mashed (CM; coarse ground grains combined with a mash supplement) starter feed with $\mathrm{AH}$ (CM-AH), (2) coarsely mashed starter feed with WS (CM-WS), (3) texturized feed starter (TF; includes steam-flaked corn, steam-rolled barley combined with a pelleted supplement) with $\mathrm{AH}$ (TF-AH), and (4) TF with WS (TFWS). Both starters had the same ingredients and nutrient compositions but differed in their physical forms. Calves were weaned on d 56 and remained in the study until d 70. All calves had free access to drinking water and the starter feeding at all times. No interaction was detected between the physical forms of starter feeds and forage source concerning starter intake, dry matter intake, metabolizable energy (ME) intake, average daily gain (ADG)/ME intake, ADG, and feed efficiency $(\mathrm{FE})$. The preweaning and overall starter feed intake, dry matter intake, and ME intake were greater for calves fed TF starter diets than those fed CM starter diets. The ADG/ME intake was greater for calves fed TF starter diets than that fed CM starter. The FE was greater for calves fed TF starter diets compared with those fed CM starter during the preweaning, postwean-
\end{abstract}

\footnotetext{
Received September 25, 2017.

Accepted February 24, 2018.

${ }^{1}$ Corresponding author: arash.azarfar@gmail.com

${ }^{2}$ Current address: Institute of Animal Science, Physiology and Hygiene Unit, University of Bonn, 53111 Bonn, Germany.
}

ing, and overall periods. The WS improved FE during the postweaning period compared with AH. The physical form of starter, forage source, and their interaction did not affect plasma glucose, triglycerides, and very low-density lipoprotein concentrations. Ruminal $\mathrm{pH}$ was greater for calves fed $\mathrm{TF}$ starter diets than those fed CM starter on d 30 of life. An interaction was observed between the physical forms of starter diets and forage source for $\beta$-hydroxybutyrate on $\mathrm{d} 28$. These results showed that when starter diets contained similar ingredients and nutrient contents, processing calf starters to reduce the number of fine particles can improve the growth performance in dairy calves. Furthermore, the provision of WS improved FE and ADG of calves during the postweaning period.

Key words: dairy calf, starter physical form, forage source

\section{INTRODUCTION}

The ultimate goal of calf nutritionists is to maximize starter intake and weight gain before weaning. Both grain processing methods and physical forms of starter feed are important for easing the transition from preruminant to mature ruminant state (Jarrah et al., 2013; Mirzaei et al., 2016; Pazoki et al., 2017). The available information to date indicates that the processing of grain and ingredients of starter feed can alter the rumen fermentation pattern and the nutrients digestibility (Huntington, 1997; Owens et al., 1997), thereby affecting starter intake and growth performance in dairy calves (Lesmeister and Heinrichs, 2004; Pezhveh et al., 2014; Pazoki et al., 2017). The literature on the effects of different physical forms of starter feed on calf performance is inconclusive. For example, Bach et al. (2007) and Porter et al. (2007) reported greater solid feed consumption in calves fed coarse ground than pelleted starter diets. In contrast, Mirzaei et al. (2016) and Pazoki et al. (2017) observed no differences in the intake and growth performance of dairy calves when comparing a ground starter feed with a textured starter feed. Franklin et al. (2003) also reported a greater intake and 
weight gain of calves fed a texturized starter than those fed a pelleted starter. The discrepancies between studies could be attributed to differences in forage provision among the studies (Imani et al., 2017), variations in the physical and chemical structure of starter diets (Khan et al., 2016), as well as the particle size of calf starters.

The particle size of calf starters has an important effect on rumen development (Suarez-Mena et al., 2016) and calf performance (Bateman et al., 2009). Feeding starter feed that is high in rapidly fermentable carbohydrates can also reduce ruminal $\mathrm{pH}$ and increase the risk of ruminal acidosis (Beharka et al., 1998). Minimal particle size is required to prevent the abnormal development of rumen papillae (Greenwood et al., 1997) and to prevent impaction of fine particles between papillae (NRC, 2001). Previous studies (Porter et al., 2007; Hill et al., 2008) indicated that starter feeds contain more than $75 \%$ of particles $>1,190 \mu \mathrm{m}$ in length are adequate to initiate rumination and to maintain normal ruminal fermentation in dairy calves that can be achieved by processing of grains in starter feeds.

Provision of dietary fiber in calf starter may be necessary to maintain abrasion in the rumen and to prevent the buildup of keratin layer on the rumen epithelium (Greenwood et al., 1997), especially if the starter diets lack an adequate particle size or texture. It has been shown that the provision of forage to young calves can improve solid feed consumption, weight gain, as well as rumen fermentation (Mirzaei et al., 2016), stimulating the muscular layer of rumen wall (Beiranvand et al., 2014; Khan et al., 2016) and rumination behavior in young calves (EbnAli et al., 2016; Hosseini et al., 2016). The results of a recent meta-analysis showed that forage provision to dairy calves had a beneficial effect on growth performance, but its effects can be modulated by forage level, forage source, and physical form of starter (Imani et al., 2017). However, limited information is available on how changes in the physical forms of starter feed and the source of supplemental dietary fiber influence the growth performance of dairy calves during the pre- and postweaning periods.

We tested the hypothesis that the effects of a physical form of starter on calf performance would depend on the source of forage. Further, we assumed that supplementing forage alleviates the adverse effects associated with feeding dairy calves by rapidly degradable carbohydrates from a coarsely mashed starter, modifies rumen conditions, and improves calf performance. Therefore, 2 physical forms of starter were fed along with 2 sources of forage to investigate their interactions on starter intake, growth performance, rumen $\mathrm{pH}$, and blood metabolites of dairy calves both during the preand postweaning periods.

\section{MATERIALS AND METHODS}

\section{Animals, Management, and Treatments}

The current study was carried out between January 28 and April 22, 2016, on a local dairy farm (GoldashtNemone Agri. Animal Production Co., Isfahan, Iran) according to the guidelines of Iranian Council of Animal Care (1995). Forty male Holstein calves (41.3 \pm 3.5 $\mathrm{kg}$ of $\mathrm{BW})$ were randomly assigned $(\mathrm{n}=10$ calves per treatment) in a $2 \times 2$ factorial arrangement of treatments with the factors of the physical form of starter diets (coarse mash vs. texturized) and forage source (alfalfa hay or wheat straw). Calves were separated from their dams immediately after birth, weighed, and moved in a naturally ventilated barn with individual pens $(1.2 \times 2.5 \mathrm{~m})$ bedded with sawdust, which was renewed every 1 to $2 \mathrm{~d}$. The calves received $2.5 \mathrm{~L}$ of colostrum at each of the first 2 feedings (i.e., within $1.5 \mathrm{~h}$ of life and $12 \mathrm{~h}$ after the first feeding). Colostrum feeding was carried out for the first $3 \mathrm{~d}$ of life. From the second feeding time until d 3 of life, all calves received colostrum and transition milk. The quality of colostrum was measured with a digital Brix refractometer (PAL-1, Atago Co. Ltd., Bellevue, WA) and was discarded if it measured lesser than 22 on the Brix scale (Bielmann et al., 2010). If the dam produced colostrum of insufficient quality or quantity, frozen-thawed colostrum with sufficient quality was fed to the calf. Calves received $5 \mathrm{~L} / \mathrm{d}$ of whole milk in steel buckets twice daily at 0800 and 1700 from d 3 to 50 of the study followed by feeding $2.5 \mathrm{~L} / \mathrm{d}$ milk until d 56 of the study (Table 1). Calves were assigned to 1 of 4 dietary treatments, including (1) coarsely mashed (CM; coarse ground grains combined with a mash supplement) starter feed with alfalfa hay (CM-AH), (2) CM starter feed with wheat straw (CM-WS), (3) texturized feed (TF; includes steam-flaked corn and steam-rolled barley combined with a pelleted supplement) starter with alfalfa hay (TF-AH), and (4) TF starter with wheat straw (TFWS; Table 1). Both starters had the same ingredients and nutrient compositions but differed in their physical form. Calves were weaned on d 56 and remained in the study until d 70 of the study. All calves had free access to clean, fresh water and the starter feed all the time. The offered feed was adjusted daily to achieve 5 to $10 \%$ orts (i.e., the portion of the starter not consumed over a 24-h period); orts were collected and weighed daily at $0800 \mathrm{~h}$. The forage-supplemented calves received a starter feed containing 5\% chopped alfalfa hay $(\mathbf{A H}$; particle size distribution: $1.0 \pm 0.0 \%$ greater than 18 $\mathrm{mm}, 17.0 \pm 0.4 \%$ between 8 and $18 \mathrm{~mm}, 41.0 \pm 1.2 \%$ between 1.18 and $8 \mathrm{~mm}$, and $41.0 \pm 0.9 \%$ less than 
Table 1. Mean $( \pm \mathrm{SD})$ chemical composition of corn, barley, soybean meal, alfalfa hay, wheat straw $(\mathrm{g} / \mathrm{kg}$ of DM), and whole milk $(\mathrm{g} / \mathrm{kg})$

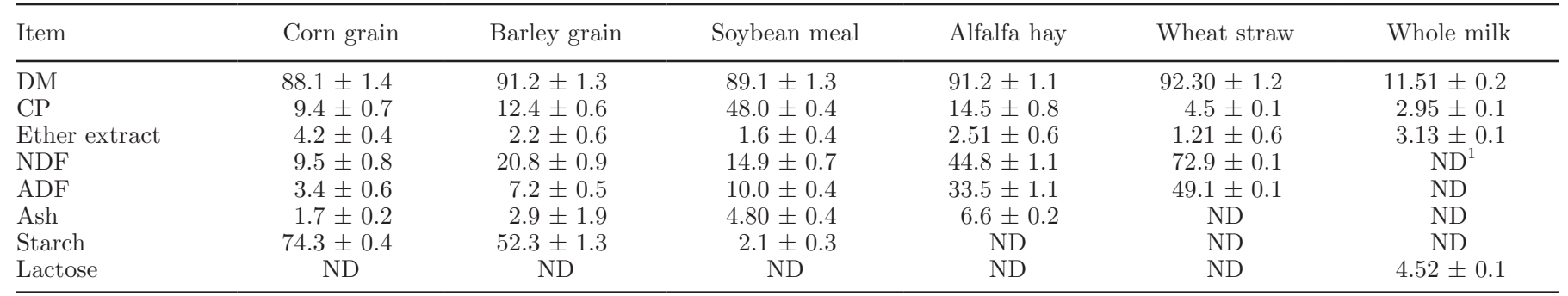

${ }^{1} \mathrm{ND}=$ not determined.

$1.18 \mathrm{~mm}$; geometric mean particle $=2.51 \pm 0.78 \mathrm{~mm}$ ) or wheat straw (WS; particle size distribution: $2.0 \pm$ $0.4 \%$ greater than $18 \mathrm{~mm}, 39.0 \pm 1.5 \%$ between 8 and $18 \mathrm{~mm}, 43.0 \pm 2.3 \%$ between 1.18 and $8 \mathrm{~mm}$, and 16.0 $\pm 1.1 \%$ less than $1.18 \mathrm{~mm}$; geometric mean particle size $=4.9 \pm 0.2 \mathrm{~mm}$ ) as a TMR mixed with concentrates throughout the study. Corn and barley grain were coarse ground using a hammer mill with a 3 -mm screen size (model 5543 GEN, Isfahan Dasht, Isfahan, Iran). The nutrient compositions of the forage and starter are given in Tables 1 and 2, respectively. The treatment of disease followed the standard operating procedures at the Goldasht-Nemone Agri. Animal Production Co. (Isfahan, Iran) and sick calves were treated by a veterinarian accordingly.

\section{Sampling and Laboratory Analyses}

Individual intakes of starter (starter feed or TMR) and milk were recorded daily, and BW were recorded weekly using an electronic balance throughout the experiment. Feed samples were collected weekly throughout the trial and stored at $-20^{\circ} \mathrm{C}$ before chemical analyses. Subsamples of feeds and refusals were mixed thoroughly, dried at $55^{\circ} \mathrm{C}$ for $48 \mathrm{~h}$, and ground to pass through a 1-mm screen in a Wiley mill (Ogaw Seiki Co. Ltd., Tokyo, Japan) before chemical analyses for DM (method 934.01; AOAC, 1990), CP (method 988.05; AOAC, 1990), lipids (AOAC, 1990; method 920.39), and NDF contents using a heat-stable $\alpha$-amylase $(100$ $\mu \mathrm{L} / 0.5 \mathrm{~g}$ of the sample) and sodium sulfite (Van Soest et al., 1991). Ten representative samples of milk were collected throughout the study and analyzed for fat, CP, lactose, and TS content by Milkoscan (Foss Electric, Hillerød, Denmark). Means of ADG and feed efficiency ( $\mathrm{kg}$ of BW gain $/ \mathrm{kg}$ of total DMI) were also calculated. Body length, wither height, heart girth, hip height, and hip width of the calves were measured according to Lesmeister and Heinrichs (2005) at weaning (d 56) and at the end of study (d 70).

Rumen fluid was collected at $\mathrm{d} 30$ and 70 by a stomach tube fitted to a vacuum pump at $3 \mathrm{~h}$ postfeeding; the first $50 \mathrm{~mL}$ was discarded to avoid possible saliva contamination. The $\mathrm{pH}$ of the original sample was measured using a $\mathrm{pH}$ meter calibrated before each reading (HI 8318; Hanna Instruments, Cluj-Napoca, Romania).

Blood samples were collected $3 \mathrm{~h}$ after the morning meal on d 28, 55, and 70 of life. Blood was taken from the jugular vein by evacuated tubes containing K2 EDTA (Becton Dickinson Vacutainer Systems, Franklin Lakes, NJ) and immediately placed on ice. All blood samples were immediately centrifuged at $2,850 \times g$ for $20 \mathrm{~min}$ at $4^{\circ} \mathrm{C}$, and $1.5 \mathrm{~mL}$ of plasma was pipetted into 2 -mL cryotubes and stored at $-20^{\circ} \mathrm{C}$ for subsequent analyses. Concentrations of blood metabolites were spectrophotometrically (UNICCO, 2100; Zistchemi Co., Tehran, Iran) determined using commercially available kits [Pars Azmoon Company, Tehran, Iran; catalog numbers: glucose (1-500-017), triglyceride (TG; 1-500-032)] according to the manufacturer's instructions. Plasma BHB was determined by autoanalyzer using a laboratory kit (Randox Laboratories Ltd., Ardmore, UK).

\section{Statistical Analyses}

Data were analyzed separately for the preweaning (from d 3-56 of the study), postweaning (from d 57-70 of the study), and overall (from d 3-70 of the study) periods. Statistical analyses were performed using the MIXED procedure of SAS (PROC MIXED, SAS 9.3, SAS Institute Inc., Cary, NC) with time (day or week) as repeated measures for starter feed intake, DMI, BW, ADG, and ME intake using the model

$$
\begin{gathered}
\mathrm{Y}_{\mathrm{ijk}}=\mu+\mathrm{A}_{\mathrm{i}}+\mathrm{F}_{\mathrm{j}}+\mathrm{P}_{\mathrm{k}}+\mathrm{T}_{\mathrm{l}}+(\mathrm{F} \times \mathrm{T})_{\mathrm{j} 1} \\
+(\mathrm{P} \times \mathrm{T})_{\mathrm{kl}}+(\mathrm{F} \times \mathrm{P})_{\mathrm{jk}}+(\mathrm{F} \times \mathrm{P} \times \mathrm{T})_{\mathrm{jkl}} \\
+\beta\left(\mathrm{X}_{\mathrm{i}}-\mathrm{X}\right)+\varepsilon_{\mathrm{ijk} \mathrm{l}},
\end{gathered}
$$

where $Y_{\mathrm{ijk}}$ is the dependent variable; $\mu$ is the overall mean; $A_{i}$ is the random effect of calf; $F_{j}$ is the fixed effect of forage source; $\mathrm{P}_{\mathrm{k}}$ is the fixed effect of physical forms of starter; $\mathrm{T}_{1}$ is the fixed effect of period, $(\mathrm{F} \times \mathrm{T})_{\mathrm{j} 1}$ 
is the interaction between forage source and period; $(\mathrm{P}$ $\times \mathrm{T})_{\mathrm{kl}}$ is the interaction between the physical forms of starter and period; $(\mathrm{F} \times \mathrm{P})_{\mathrm{jk}}$ is the interaction between forage source and the physical forms of starter; $(\mathrm{F} \times$ $\mathrm{P} \times \mathrm{T})_{\mathrm{jkl}}$ is the tripartite effect of forage source, the physical forms of starter, and period; $\beta\left(\mathrm{X}_{\mathrm{i}}-\mathrm{X}\right)$ is the covariate variable (for $\mathrm{BW}$ and skeletal growth, the initial values were considered as covariates); and $\varepsilon_{\mathrm{ijkl}}$ is the random residual error, assuming $\mathrm{N}\left(0, \sigma^{2}\right)$, where $\sigma^{2}$ is variance. Before analyses, all data were screened for normality using the UNIVARIATE procedure of SAS. Autoregressive covariance structure was the best fit for these data as determined by the lowest Akaike's information criterion. Initial BW was considered as a covariate for the weaning and final BW (d 56 and 70) analysis. Data on blood metabolites (d 28, 55, and 70) and skeletal growth parameters (d 56 and 70) were analyzed as a completely randomized design from dietary treatments. Rumen fermentation and structural growth variables were analyzed using a similar model but without the effect of time. Least squares means for treatment effects were separated by the use of PDIFF statement when the overall F-test was $P \leq 0.05$.

\section{RESULTS}

\section{Intake and Growth Performance}

The results on DMI, starter intake, forage intake, ME intake, ADG, and feed efficiency are presented in Table 3. No interaction was found between the physical forms of starter diets and forage source with respect to starter intake, DMI, ME intake, ADG, ADG/ME intake, and feed efficiency $(\mathbf{F E})$. For total DMI, starter feed in-

Table 2. Ingredients, chemical composition, and particle size distribution of experimental diets

\begin{tabular}{|c|c|c|c|c|}
\hline \multirow[b]{2}{*}{ Item } & \multicolumn{4}{|c|}{ Treatment } \\
\hline & Alfalfa hay & Wheat straw & Alfalfa hay & Wheat straw \\
\hline \multicolumn{5}{|l|}{ Ingredient, $\%$ of $\mathrm{DM}$} \\
\hline Alfalfa hay & 5.0 & - & 5.0 & - \\
\hline Wheat straw & - & 5.0 & - & 5.0 \\
\hline Steam-rolled barley & - & - & 18.0 & 18.7 \\
\hline Steam-flaked corn & - & - & 37.5 & 35.0 \\
\hline Soybean $_{\text {meal }}^{1}$ & 23.3 & 23.4 & 23.0 & 24.3 \\
\hline Pishgam premix ${ }^{1,2}$ & 15.0 & 15.2 & 14.8 & 15.2 \\
\hline Salt $^{1}$ & 0.50 & 0.50 & 0.50 & 0.50 \\
\hline Calcium carbonate $^{1}$ & 1.20 & 1.30 & 1.20 & 1.30 \\
\hline \multicolumn{5}{|c|}{ Chemical composition, $\mathrm{g} / \mathrm{kg}$ of $\mathrm{DM}$} \\
\hline $\mathrm{NFC}^{3}$ & 51.0 & 50.0 & 51.0 & 50.0 \\
\hline $\mathrm{Ca}^{4}$ & 0.82 & 0.80 & 0.82 & 0.80 \\
\hline $\mathrm{P}^{4}$ & 0.47 & 0.47 & 0.45 & 0.46 \\
\hline \multicolumn{5}{|c|}{ Particles retained on the sieve, $\mathrm{g} / \mathrm{kg}$} \\
\hline $4.75 \mathrm{~mm}$ & $15.6 \pm 0.4$ & $20.6 \pm 0.6$ & $18.4 \pm 1.0$ & $19.6 \pm 0.6$ \\
\hline $2.36 \mathrm{~mm}$ & $20.4 \pm 1.0$ & $25.2 \pm 3.0$ & $71.7 \pm 0.3$ & $69.1 \pm 0.6$ \\
\hline $1.18 \mathrm{~mm}$ & $14.9 \pm 0.6$ & $12.0 \pm 0.8$ & $4.6 \pm 0.5$ & $4.2 \pm 0.8$ \\
\hline $0.6 \mathrm{~mm}$ & $27.8 \pm 0.4$ & $24.6 \pm 0.9$ & $2.8 \pm 0.4$ & $3.3 \pm 0.4$ \\
\hline $0.3 \mathrm{~mm}$ & $16.4 \pm 0.6$ & $13.8 \pm 2.4$ & $1.8 \pm 0.3$ & $2.5 \pm 0.4$ \\
\hline $0.15 \mathrm{~mm}$ & $4.2 \pm 0.3$ & $3.3 \pm 0.8$ & $0.6 \pm 0.0$ & $1.1 \pm 0.1$ \\
\hline Pan & $0.5 \pm 0.0$ & $0.4 \pm 0.2$ & $0.0 \pm 0.0$ & $0.0 \pm 0.0$ \\
\hline $\mathrm{GMPL}^{5}(\mathrm{~mm})$ & $1.03 \pm 0.01$ & $1.23 \pm 0.09$ & $2.36 \pm 0.05$ & $2.30 \pm 0.03$ \\
\hline \multicolumn{5}{|c|}{${ }^{1}$ All these ingredients were pelleted for texturized starter. } \\
\hline \multicolumn{5}{|c|}{$\begin{array}{l}{ }^{2} \text { Contained per kilogram of supplement (unless noted): } \mathrm{DM}=93 \%, \mathrm{CP}=29 \% \text {, fat }=6.5 \%, \mathrm{ME}=2.31 \mathrm{Mcal}, \mathrm{NE} \mathrm{G}_{\mathrm{G}}=0.85 \mathrm{Mcal}, \mathrm{NDF}=17.5 \% \text {, } \\
\mathrm{Ca}=0.65 \%, \mathrm{P}=0.77 \%, \mathrm{NFC}=29 \%, \mathrm{Mg}=2 \mathrm{~g}, \mathrm{~K}=0.99 \mathrm{~g}, \mathrm{Na}=1.6 \mathrm{~g}, \mathrm{Cl}=0.1 \mathrm{mg}, \mathrm{Co}=23 \mathrm{mg}, \mathrm{Mn}=43 \mathrm{mg}, \mathrm{Se}=0.1 \mathrm{mg}, \mathrm{Zn}=43 \mathrm{mg} \text {, } \\
\text { vitamin } \mathrm{A}=12,000 \mathrm{IU} \text {, vitamin } \mathrm{D}_{3}=5,000 \mathrm{IU} \text {, vitamin } \mathrm{E}=100 \mathrm{IU}\end{array}$} \\
\hline
\end{tabular}


take (Figure 1), and ME intake, we detected a physical forms of starter $\times$ week interaction $(P<0.01)$, whereas TF calves had greater intakes of total DM, starter feed, and ME compared with $\mathrm{CM}$ calves in wk $4,5,6,7$, and 8 of the experiment. Average daily gain $(P<0.01)$ and ADG/ME intake $(P=0.02)$ were also affected by physical forms of starter $\times$ week interaction so that TF-fed calves had greater ADG and ADG/ME intake than CM-fed calves in wk 4, 5, 6, 7, and 8 and during the postweaning period. A physical form of starter $\times$ week interaction was observed for $\mathrm{FE}$ with $\mathrm{TF}$ calves had a higher FE than AH calves in wk 6, 7, 8, 9, and $10(P<0.05)$. A forage source $\times$ week interaction was observed for overall ADG, ADG/ME intake, and FE so that WS-fed calves had greater ADG, ADG/ME intake, and FE than AH-fed calves in wk 6, 7, and 8 and during the postweaning period $(P=0.01)$.

The preweaning $(1.17$ vs. $1.00 \mathrm{~kg} / \mathrm{d} ; P=0.01)$ and overall DMI (1.50 vs. $1.38 \mathrm{~kg} / \mathrm{d} ; P=0.03)$ were greater for calves fed $\mathrm{TF}$ starter diets than those fed $\mathrm{CM}$ starter diets. The preweaning $(0.53$ vs. $0.37 \mathrm{~kg} / \mathrm{d} ; P$ $=0.01)$ and overall starter feed intake (0.85 vs. 0.72 $\mathrm{kg} / \mathrm{d} ; P=0.01$ ) were greater for calves fed TF starter diets compared with calves fed CM starter diets. The preweaning, postweaning, and overall starter feed and DM intake were similar in AH- and WS-fed calves. The preweaning ( 4.63 vs. $4.17 \mathrm{Mcal} / \mathrm{d} ; P=0.01)$ and overall ME intake (5.33 vs. $5.00 \mathrm{Mcal} / \mathrm{d} ; P=0.04$ ) were greater in calves fed TF starter diets than in calves fed CM starter diets. The preweaning, postweaning, and overall ME intake were similar for AH- compared with WS-supplemented calves.

In the current study, the preweaning (0.568 vs. 0.455 $\mathrm{kg} / \mathrm{d}, P=0.01)$, postweaning (1.125 vs. $0.917 \mathrm{~kg} / \mathrm{d}, P$ $=0.01$ ), and overall ADG (0.753 vs. $0.609 \mathrm{~kg} / \mathrm{d}, P=$ 0.01) were greater in TF calves than in CM calves. The postweaning and overall ADG were greater for WS forage-supplemented calves compared with $\mathrm{AH}$ foragesupplemented calves. The ADG/ME intake (0.139 vs. $0.120 \mathrm{~kg} / \mathrm{Mcal} ; P=0.01)$ were greater for TF calves than $\mathrm{CM}$ calves. The preweaning $(0.49$ vs. $0.43 ; P=$ 0.01 ), postweaning ( 0.53 vs. $0.44 ; P=0.01$ ), and overall FE $(0.50$ vs. $0.43 ; P=0.01)$ were greater for TF-fed calves compared with CM-fed calves. The postweaning FE were greater $(P=0.01)$ in WS- than in AHsupplemented calves.

Calf BW was similar at the start of the experiment. No interaction was observed between the physical forms of starter diets and forage source for weaning and final BW (Table 4). Weaning and final BW, body length, hip height, hip width (56 and $70 \mathrm{~d}$ of age), wither height $(56 \mathrm{~d})$, and heart girth $(70 \mathrm{~d})$ were greater $(P=0.01$; Table 4) for calves offered TF starter feed than those fed CM starter diets.

\section{Blood Metabolites and Rumen pH}

An interaction was observed between the physical form of starter diets and forage source for BHB during d $28(P=0.05)$. The physical form of starter, forage source, and their interactions did not affect plasma glucose and triglycerides concentrations. Ruminal $\mathrm{pH}$ (6.09 vs. $5.77 ; P=0.01$; Table 5 ) was greater for calves fed TF starter diets than that fed CM starter on d 30 of life.

\section{DISCUSSION}

\section{Intake and Growth Performance}

The lower consumption of starter feed and DM, in our study, for calves fed CM than those fed TF was likely due to reduced ruminal $\mathrm{pH}$ (Table 5). Consumption of fine particle size diets has been considered as a risk factor for the proper rumen function and feed intake (Greenwood et al., 1997). Similarly, lower starter feed intake was previously reported for calves fed starter feed with fine particles than those fed starter feed with large particles (Kertz et al., 1979; Porter et al., 2007). Bateman et al. (2009) found that decreasing starter feed mean particle length from 2.03 to $0.81 \mathrm{~mm}$ decreased postweaning and overall starter intake of calves by 250 and $137 \mathrm{~g} / \mathrm{d}$, respectively. The previous report showed a positive relationship between rumen $\mathrm{pH}$ and starter feed intake (Thomas and Hinks, 1982). In the current study, the inclusion of forage in CM starter diets led to a higher rumen $\mathrm{pH}$ and, consequently, increased starter feed intake during the postweaning period. Laarman and Oba (2011) showed that hay intake was negatively correlated with the area under $\mathrm{pH} 5.8$ in the rumen (with a breakpoint at $0.080 \mathrm{~kg} / \mathrm{d}$ intake) for calves, suggesting forage intake may play an important role in mitigating ruminal acidosis in dairy calves during the weaning transition.

In the present study, postweaning forage provision enhanced starter intake in CM-fed calves, which was in line with the recent meta-analysis of Imani et al. (2017), who showed that forage supplementation improved starter feed intake in the ground or pelleted starter-fed calves but not in texturized starter-fed calves. It is well known that the physical form of starter feed influences the rumen fermentation and $\mathrm{pH}$ (Imani et al., 2017), and feeding calves with finely ground starter feed high in rapidly fermentable carbohydrates reduces ruminal pH and starter feed intake (Ghassemi-Nejad et al., 2012; Pazoki et al., 2017). Similar to dairy cows, calves may experience ruminal acidosis that can be alleviated by forage supplementation (Imani et al., 2017). However, studies investigating the effects of forage provision to 
PHYSICAL FORMS OF STARTER AND FORAGE IN CALVES

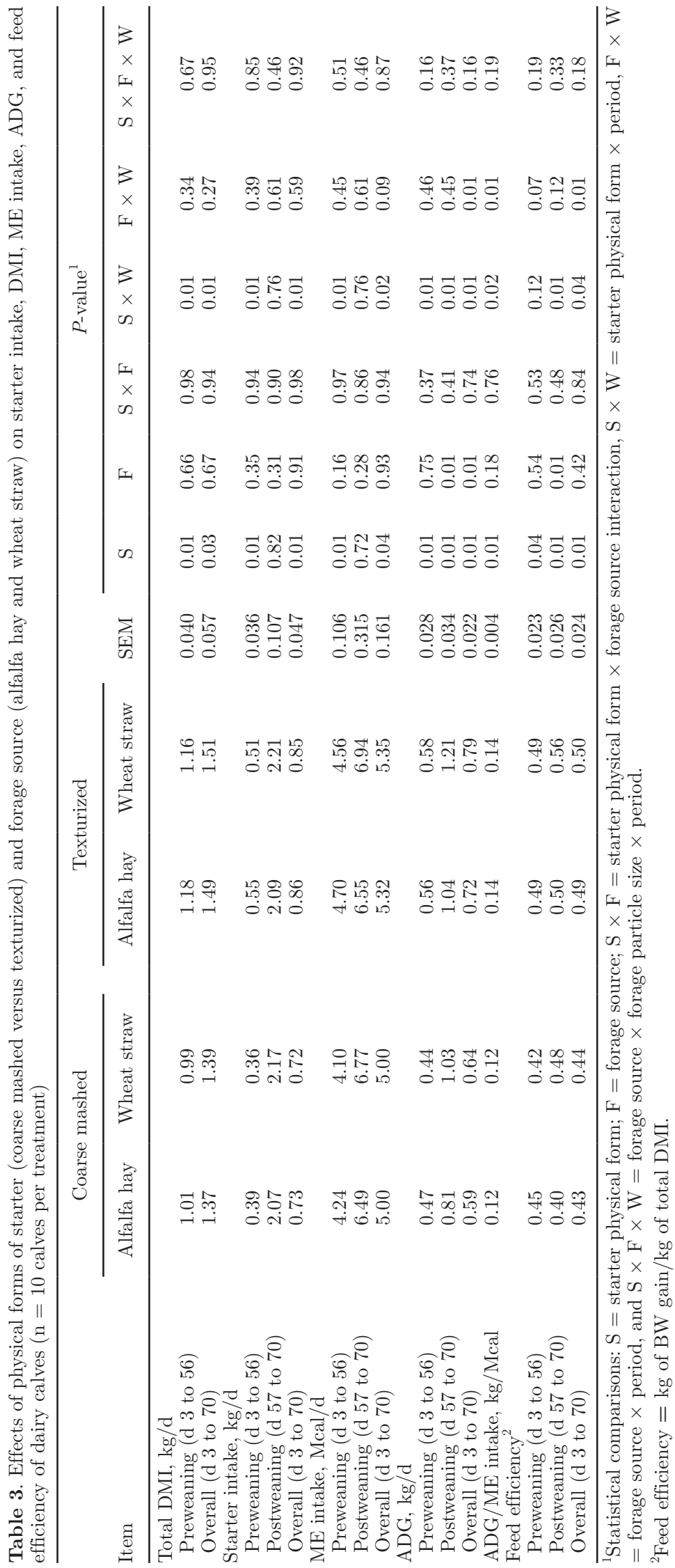




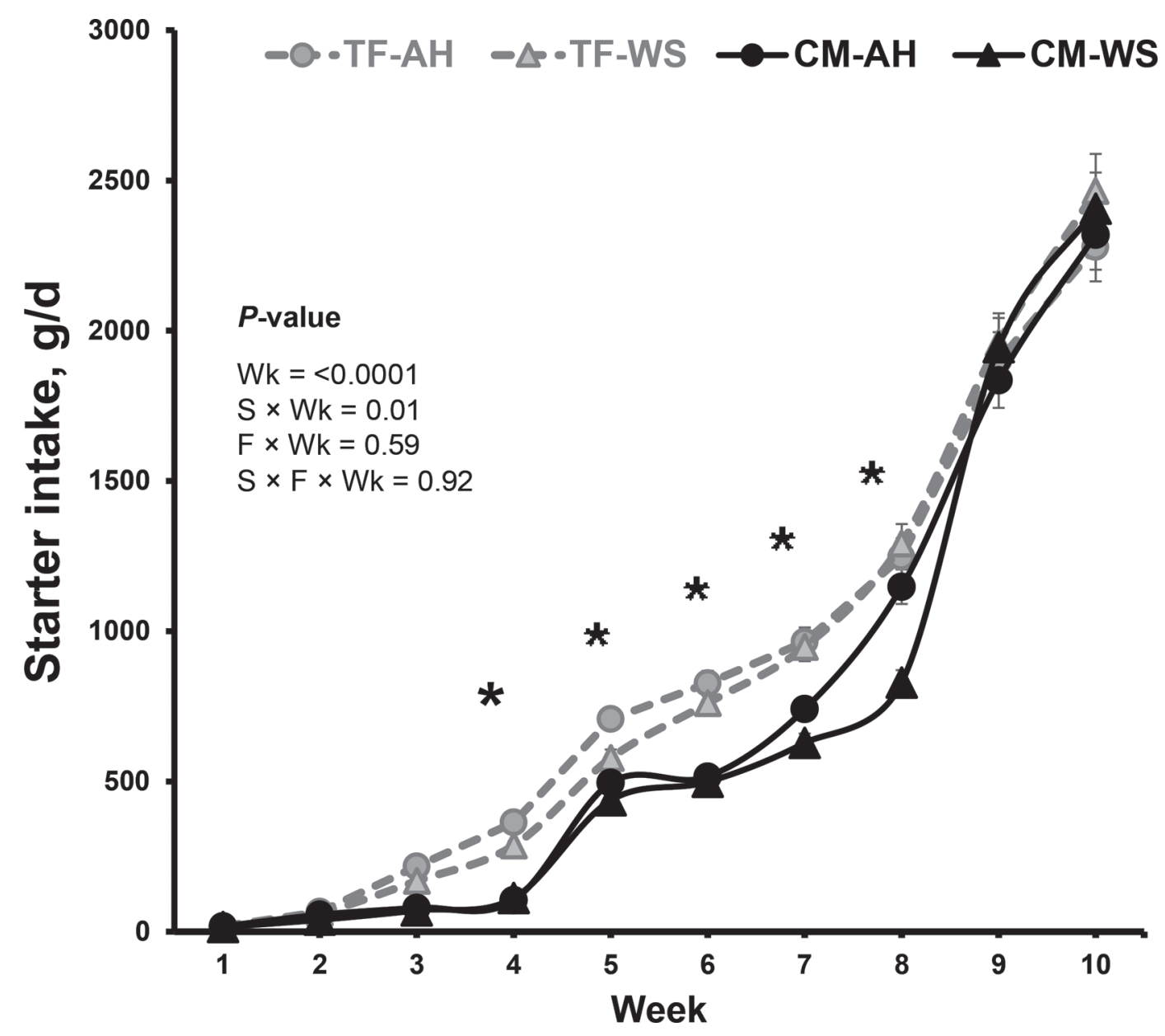

Figure 1. Effects of physical forms of starter (coarse mashed and texturized) and forage source [alfalfa hay (AH) and wheat straw] on starter intake of dairy calves $(\mathrm{n}=10$ calves per treatment). Treatments were $(1)$ a coarsely mashed feed (CM; coarse ground grains combined with a mash supplement) with AH supplementation (CM-AH), (2) a CM feed with wheat straw (WS) supplementation (CM-WS), (3) a texturized feed (TF; includes steam-flaked corn, steam-rolled barley combined with a pelleted supplement) with AH supplementation (TF-AH), and (4) a TF with WS supplementation (TF-WS). *Significantly different for $\mathrm{S} \times \mathrm{Wk}$.

dairy calves on starter intake have yielded inconsistent results owing to factors such as forage levels, forage sources, and physical form of starter feeds used (Imani et al., 2017).

In the current study, the lower ADG in calves offered CM starters were in line with the results of Bateman et al. (2009), who reported that the fine particle sized starter diets leads to poor acceptability, low intake, and decreased weight gain in calves compared with the large particle sized starter diets. The greater pre- and postweaning ADG obtained with the TF diets compared with the CM diets, in our study, was due to the greater starter intake and $\mathrm{FE}$ of $\mathrm{TF}$ - rather than CM-fed calves, which was in agreement with a previous report (Porter et al., 2007). However, our finding was inconsistent with that reported by Mirzaei et al. (2016), who found no difference in ADG between calves fed a $\mathrm{TF}$ starter or a finely ground starter.
Similar to our findings, several studies have observed increased ADG in calves provided with forage, either during the preweaning stage (Mirzaei et al., 2016, 2017) or the postweaning stage (Terré et al., 2013; Mirzaei et al., 2017). In contrast, some studies reported a decrease in ADG of dairy calves over the weaning transition (Horvath and Miller-Cushon., 2017) or when NDF from roughage exceeded $1.5 \%$ of DM (Hill et al., 2010). Results regarding ADG in the current study were in line with those reported by Imani et al. (2017), where ADG improved by more than $50 \mathrm{~g} / \mathrm{d}$ with forage provision to dairy calves. In the present study, provision of WS to dairy calves increased postweaning ADG compared with AH (Table 3). Our results regarding ADG were in line with those reported by Castells et al. (2012), who reported that free-choice provision of WS to young calves improved ADG compared with AH. However, a recent meta-regression analysis revealed that changes 
Table 4. Effects of the physical forms of starter (coarse mashed versus texturized) and forage source (alfalfa hay and wheat straw) on BW and body measurements of dairy calves $(n=10$ calves per treatment)

\begin{tabular}{|c|c|c|c|c|c|c|c|c|}
\hline \multirow[b]{2}{*}{ Item } & \multicolumn{2}{|c|}{ Coarse mashed } & \multicolumn{2}{|c|}{ Texturized } & \multirow[b]{2}{*}{ SEM } & \multicolumn{3}{|c|}{$P$-value ${ }^{1}$} \\
\hline & Alfalfa hay & Wheat straw & Alfalfa hay & Wheat straw & & S & $\mathrm{F}$ & $\mathrm{S} \times \mathrm{F}$ \\
\hline Initial (d 3) & 41.55 & 41.78 & 41.33 & 41.22 & 1.20 & 0.74 & 0.96 & 0.90 \\
\hline Weaning (d 56) & 67.77 & 65.60 & 74.14 & 73.72 & 1.83 & 0.01 & 0.48 & 0.63 \\
\hline Final (d 70) & 79.16 & 80.10 & 88.68 & 90.72 & 2.18 & 0.01 & 0.50 & 0.79 \\
\hline \multicolumn{9}{|l|}{ Body length, cm } \\
\hline \multicolumn{9}{|l|}{ Wither height, cm } \\
\hline d 56 & 85.2 & 85.5 & 86.8 & 87.3 & 0.66 & 0.01 & 0.53 & 0.92 \\
\hline d 70 & 91.6 & 92.0 & 93.3 & 93.8 & 0.89 & 0.07 & 0.58 & 0.98 \\
\hline \multicolumn{9}{|l|}{ Heart girth, cm } \\
\hline d 56 & 99.9 & 99.8 & 102.4 & 99.6 & 1.06 & 0.28 & 0.16 & 0.21 \\
\hline d 70 & 104.9 & 104.2 & 108.4 & 107.4 & 1.09 & 0.01 & 0.43 & 0.88 \\
\hline \multicolumn{9}{|l|}{ Hip width, cm } \\
\hline
\end{tabular}

${ }^{1}$ Statistical comparisons: $\mathrm{S}=$ starter physical form; $\mathrm{F}=$ forage source; $\mathrm{S} \times \mathrm{F}=$ starter physical form by forage source interaction.

in forage sources similarly affected ADG during the postweaning period (Imani et al., 2017). In the current study, the increased postweaning ADG and FE observed with the inclusion of WS in CM and TF starter diets compared with AH supplementation was likely due to the sufficient supply of effective fibers to stimulate chewing activity and salivation, resulting in more rumen environment stability and fiber digestion, which may cause improved FE. Similarly, Omidi-Mirzaei et al. (2018) reported that calves fed WS spent greater time for ruminating compared with those fed $\mathrm{AH}$ during the transition weaning.
Similar to our findings, Mirzaei et al. (2016) did not observe any interactions between the physical forms of starter (finely ground vs. texturized forms) and forage provision (corn silage) on $\mathrm{FE}$ of dairy calves during the pre- and postweaning periods. Previously, Crocker et al. (1998) reported that the starch digestibility was greater for steam-flaked grains than ground grains. Steam-flaking results in gelatinization of starch, rendering the starch into a more accessible form of microbial degradation in the rumen (Ghassemi-Nejad et al., 2012). Therefore, the higher FE in calves fed TF (containing steam-flaked corn and steam-rolled barley)

Table 5. Effects of the physical forms of starter (coarse mashed versus texturized) and forage source (alfalfa hay and wheat straw) on ruminal $\mathrm{pH}$ and blood metabolites of dairy calves $(\mathrm{n}=10$ calves per treatment)

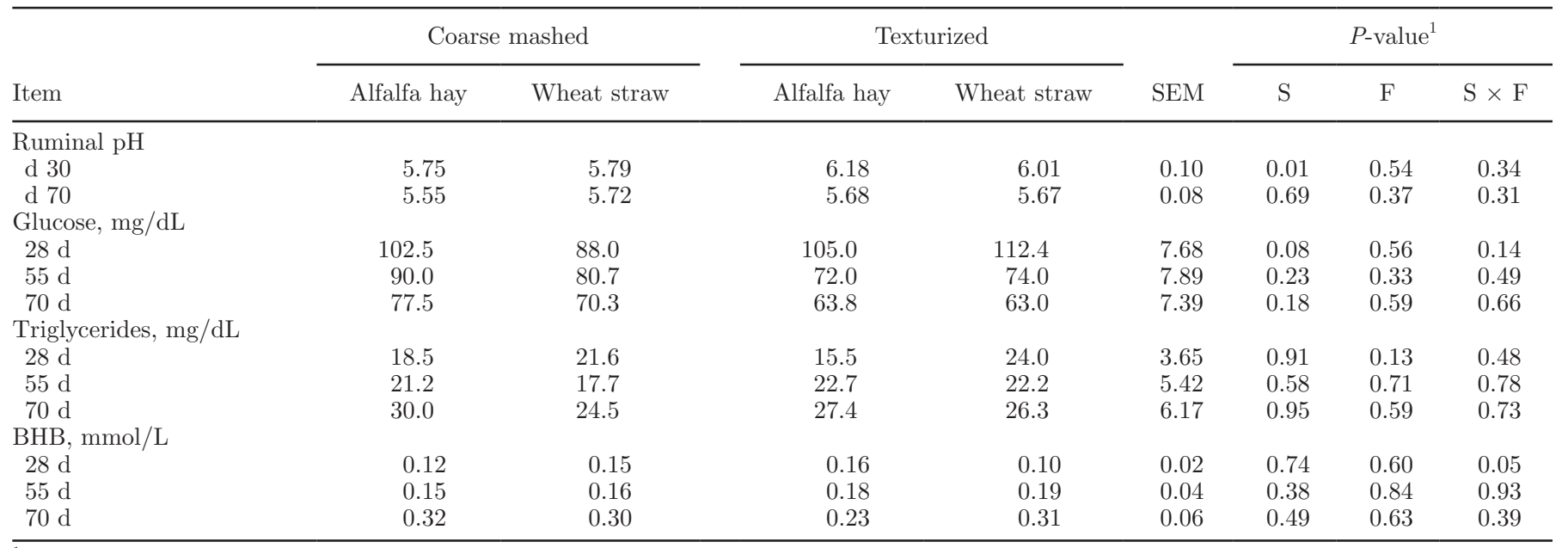

${ }^{1}$ Statistical comparisons: $\mathrm{S}=$ starter physical form; $\mathrm{F}=$ forage source; $\mathrm{S} \times \mathrm{F}=$ starter physical form by forage source interaction. 
than those fed CM starter diets could be attributed to the higher nutrients digestibility of TF starter compared with CM starter. In the current study, TF starter improved BW of dairy calves at weaning and the end of the study. These results were inconsistent with the results of Pazoki et al. (2017) and Mirzaei et al. (2017), who reported similar final BW and body measurements in calves fed ground starter feed and those fed the TF form. The discrepancy between our results and others reports might be partly attributed to the differences in forage source and level, ingredient particle size, and mean particle sizes of the TF starters.

\section{Blood Metabolites and Rumen pH}

Average rumen $\mathrm{pH}$ was reported to be between 5.37 and 5.31 in calves fed finely ground starter feeds without forage supplementation (Mirzaei et al., 2016) and 5.30 to 5.41 when calves were fed a TF starter (Pazoki et al., 2017), which were lower than our results during the preweaning stage, although variability in mean ruminal $\mathrm{pH}$ is high in dairy calves (Laarman and Oba, 2011). Previous reports showed that ruminal pH remained under 6.0 in young calves, particularly those fed finely ground diets (Greenwood et al., 1997; Beharka et al., 1998). Further, finely ground starter diets that are high in rapidly fermentable carbohydrates could further reduce the rumen $\mathrm{pH}$ of preweaning calves (GhassemiNejad et al., 2012). Recently, Imani et al. (2017) found that forage provision to dairy calves increased ruminal $\mathrm{pH}$ during the milk-feeding and postweaning periods, confirming our findings.

Similar levels of plasma glucose among the treatments in our study indicated that calves were similar in energy status across diets (Senevirathne et al., 2017). As calves age, the concentration of plasma BHB increases, mainly due to an increase in starter feed intake and consequent rumen development (Nemati et al., 2015). In the current study, no differences were observed in plasma concentrations of triglycerides in preweaning calves. The lack of starter physical forms effects on plasma concentration of glucose and triglycerides in our study was consistent with the results of Moeini et al. (2017), who found similar plasma glucose and triglycerides in calves fed ground starters (with a mean particle size of $0.72 \mathrm{~mm}$ in diameter) than those fed TF starters (with a mean particle size of $3.61 \mathrm{~mm}$ in diameter plus steam-flaked corn and barley). Glucose and BHB data for the effect of forage provision (15\% of $\mathrm{DM})$ to calves in the current study was consistent with the results of Mirzaei et al. (2017), who observed similar plasma glucose levels between calves supplemented and not supplemented with forage, but in contrast to some previous studies (Khan et al., 2011; Terré et al., 2013) in which inclusion of forage in the starter diets increased plasma BHB concentrations in dairy calves. Recently, Suarez-Mena et al. (2017) observed a positive linear relationship between starter intake and blood BHB level; however, blood BHB concentration was not only affected by starter feed intake, but it was also affected by time of day, stress, and intake restriction. As such, further work in this area is needed.

\section{CONCLUSIONS}

In the current study, no interaction was detected between the physical form of starter diets and forage source with respect to starter intake and DMI, ME intake, ADG, ADG/ME intake, and FE contradicted with our hypothesis. As expected, the physical form of starter interacted with forage source in affecting BHB. However, regardless of the physical form of starter, WS provision improves postweaning ADG and FE compared with $\mathrm{AH}$ supplementation. In summary, the TF starter feeds had more benefits on growth performance and efficiency of dairy calves over the weaning transition than CM starter feed.

\section{ACKNOWLEDGMENTS}

The authors acknowledge Pishgam Damparvar Sepahan Co. (Isfahan, Iran) for financial support of this study. The authors appreciate Hamid Memar, Mohammad Moshtaghian, Mohsen Moazeni, Behzad Akhlaghi, and Farzad Hashemzadeh (Isfahan University of Technology) for their help.

\section{REFERENCES}

American Society of Agricultural Engineers. 1983. Method of determining and expressing fineness of feed materials by sievingASAE standards. Agricultural Engineers Yearbook of Standards. ASAE, St. Joseph, MI.

AOAC. 1990. Official Methods of Analysis. 15th ed. Association of Official Analytical Chemists, Arlington, VA.

Bach, A., A. Giménez, J. L. Juaristi, and J. Ahedo. 2007. Effects of physical form of a starter for dairy replacement calves on feed intake and performance. J. Dairy Sci. 90:3028-3033. https://doi .org/10.3168/jds.2006-761.

Bateman, H. G., II, T. M. Hill, J. M. Aldrich, and R. L. Schlotterbeck. 2009. Effects of corn processing, particle size, and diet form on performance of calves in bedded pens. J. Dairy Sci. 92:782-789. https://doi.org/10.3168/jds.2008-1242.

Beharka, A. A., T. G. Nagaraja, J. L. Morrill, G. A. Kennedy, and R. D. Klemm. 1998. Effects of form of the diet on anatomical, microbial, and fermentative development of the rumen of neonatal calves. J. Dairy Sci. 81:1946-1955. https://doi.org/10.3168/jds .S0022-0302(98)75768-6.

Beiranvand, H., G. R. Ghorbani, M. Khorvash, A. Nabipour, M. Dehghan-Banadaky, A. Homayouni, and S. Kargar. 2014. Interactions of alfalfa hay and sodium propionate on dairy calf performance 
and rumen development. J. Dairy Sci. 97:2270-2280. https://doi .org/10.3168/jds.2012-6332.

Bielmann, V., J. Gillan, N. R. Perkins, A. L. Skidmore, S. Godden, and K. E. Leslie. 2010. An evaluation of Brix refractometry instruments for measurement of colostrum quality in dairy cattle. J. Dairy Sci. 93:3713-3721. https://doi.org/10.3168/jds.2009-2943.

Castells, L., A. Bach, G. Araujo, C. Montoro, and M. Terré. 2012. Effect of different forage sources on performance and feeding behavior of Holstein calves. J. Dairy Sci. 95:286-293. https://doi.org/10 $.3168 /$ jds.2011-4405.

Crocker, L. M., E. J. DePeters, J. G. Fadel, H. Perez-Monti, S. J. Taylor, J. A. Wyckoff, and R. A. Zinn. 1998. Influence of processed corn grain in diets of dairy cows on digestion of nutrients and milk composition. J. Dairy Sci. 81:2394-2407. https://doi.org/10.3168/ jds.S0022-0302(98)70131-6.

EbnAli, A., M. Khorvash, G. R. Ghorbani, A. Nargeskhani, M. Malekkhahi, M. Mirzaei, A. Pezeshki, and M. H. Ghaffari. 2016. Effects of forage offering method on performance, rumen fermentation, nutrient digestibility, blood metabolites, and nutritional behavior in Holstein dairy calves. J. Anim. Physiol. Anim. Nutr. (Berl.) 100:820-827. https://doi.org/10.1111/jpn.12442.

Franklin, S. T., D. M. Amaral-Phillips, J. A. Jackson, and A. A. Campbell. 2003. Health and performance of Holstein calves that suckled or were hand-fed colostrum and were fed one of three physical forms of starter. J. Dairy Sci. 86:2145-2153. https://doi .org/10.3168/jds.S0022-0302(03)73804-1.

Ghassemi-Nejad, J., N. Torbatinejad, A. A. Naserian, S. Kumar, J. D. Kim, Y. H. Song, C. S. Ra, and K. I. Sung. 2012. Effects of processing of starter diets on performance, nutrient digestibility, rumen biochemical parameters and body measurements of Brown Swiss dairy calves. Asian-Australas. J. Anim. Sci. 25:980-987. https://doi.org/10.5713/aj.2011.11457.

Greenwood, R. H., J. L. Morrill, and E. C. Titgemeyer. 1997. Using dry feed intake as a percentage of initial body weight as a weaning criterion. J. Dairy Sci. 80:2542-2546. https://doi.org/10.3168/jds .S0022-0302(97)76208-8.

Hill, T. M., H. G. Bateman, J. M. Aldrich, and R. L. Schlotterbeck. 2008. Effects of the amount of chopped hay or cottonseed hulls in a textured calf starter on young calf performance. J. Dairy Sci. 91:2684-2693. https://doi.org/10.3168/jds.2007-0935.

Hill, T. M., H. G. Bateman, J. M. Aldrich, and R. L. Schlotterbeck. 2010. Roughage amount, source, and processing for diets fed to weaned dairy calves. Prof. Anim. Sci. 26:181-187. https://doi.org/ 10.15232/S1080-7446(15)30578-7.

Horvath, K. C., and E. K. Miller-Cushon. 2017. The effect of milkfeeding method and hay provision on the development of feeding behavior and non-nutritive oral behavior of dairy calves. J. Dairy Sci. 100:3949-3957. https://doi.org/10.3168/jds.2016-12223.

Hosseini, S. M., G. R. Ghorbani, P. Rezamand, and M. Khorvash. 2016. Determining optimum age of Holstein dairy calves when adding chopped alfalfa hay to meal starter diets based on measures of growth and performance. Animal 10:607-615. https://doi.org/ 10.1017/S1751731111002499.

Huntington, G. B. 1997. Starch utilization by ruminants: From basics to the bunk. J. Anim. Sci. 75:852-867.

Imani, M., M. Mirzaei, B. Baghbanzadeh-Nobari, and M. H. Ghaffari. 2017. Effects of forage provision to dairy calves on growth performance and rumen fermentation: A meta-analysis and metaregression. J. Dairy Sci. 100:1136-1150. https://doi.org/10.3168/ jds.2016-11561.

Iranian Council of Animal Care. 1995. Guide to the Care and Use of Experimental Animals. Isfahan University of Technology, Isfahan, Iran.

Jarrah, A., G. R. Ghorbani, P. Rezamand, and M. Khorvash. 2013. Effects of processing methods of barley grain in starter diets on feed intake and performance of dairy calves. J. Dairy Sci. 96:7269-7273. https://doi.org/10.3168/jds.2013-6645.

Kertz, A. F., L. R. Prewitt, and J. P. Everett Jr. 1979. An early weaning calf program: Summarization and review. J. Dairy Sci.
62:1835-1843. https://doi.org/10.3168/jds.S0022-0302(79)83508 $-0$.

Khan, M. A., A. Bach, D. M. Weary, and M. A. G. von Keyserlingk. 2016. Invited review: Transitioning from milk to solid feed in dairy heifers. J. Dairy Sci. 99:885-902. https://doi.org/10.3168/ jds.2015-9975.

Khan, M. A., D. M. Weary, and M. A. G. von Keyserlingk. 2011. Hay intake improves performance and rumen development of calves fed higher quantities of milk. J. Dairy Sci. 94:3547-3553. https://doi .org/10.3168/jds.2010-3871.

Laarman, A. H., and M. Oba. 2011. Short communication: Effect of calf starter on rumen $\mathrm{pH}$ of Holstein dairy calves at weaning. J. Dairy Sci. 94:5661-5664. https://doi.org/10.3168/jds.2011-4273.

Lesmeister, K. E., and A. J. Heinrichs. 2004. Effects of corn processing on growth characteristics, rumen development, and rumen parameters in neonatal dairy calves. J. Dairy Sci. 87:3439-3450. https:// doi.org/10.3168/jds.S0022-0302(04)73479-7.

Lesmeister, K. E., and A. J. Heinrichs. 2005. Effects of adding extra molasses to a texturized calf starter on rumen development, growth characteristics, and blood parameters in neonatal dairy calves. J. Dairy Sci. 88:411-418. https://doi.org/10.3168/jds .S0022-0302(05)72702-8.

Mirzaei, M., M. Khorvash, G. R. Ghorbani, M. Kazemi-Bonchenari, and M. H. Ghaffari. 2017. Growth performance, feeding behavior, and selected blood metabolites of Holstein dairy calves fed restricted amounts of milk: No interactions between sources of finely ground grain and forage provision. J. Dairy Sci. 100:1086-1094. https://doi.org/10.3168/jds.2016-11592.

Mirzaei, M., M. Khorvash, G. R. Ghorbani, M. Kazemi-Bonchenari, A. Riasi, A. Soltani, B. Moshiri, and M. H. Ghaffari. 2016. Interactions between the physical form of starter (mashed versus textured) and corn silage provision on performance, rumen fermentation, and structural growth of Holstein calves. J. Anim. Sci 94:678-686. https://doi.org/10.2527/jas.2015-9670.

Moeini, H. A., H. Mahdavi, A. Riasi, G. R. Ghorbani, E. Oskoueian, M. A. Khan, and M. H. Ghaffari. 2017. Effects of physical form of starter and forage provision to young calves on blood metabolites, liver composition and intestinal morphology. J. Anim. Physiol. Anim. Nutr. (Berl). 101:755-766. https://doi.org/10.1111/jpn .12485 .

Nemati, M., H. Amanlou, M. Khorvash, B. Moshiri, M. Mirzaei, M. A. Khan, and M. H. Ghaffari. 2015. Rumen fermentation, blood metabolites, and growth performance of calves during transition from liquid to solid feed: Effects of dietary level and particle size of alfalfa hay. J. Dairy Sci. 98:7131-7141. https://doi.org/10.3168/ jds.2014-9144.

NRC. 2001. Nutrient Requirements of Dairy Cattle. 7th rev. ed. Natl. Acad. Press, Washington, DC.

Omidi-Mirzaei, H., A. Azarfar, M. Mirzaei, A. Kiani, and M. H. Ghaffari. 2018. Effects of forage source and forage particle size as a free-choice provision on growth performance, rumen fermentation, and behavior of dairy calves fed texturized starters. J. Dairy Sci. https://doi.org/10.3168/jds.2017-13990.

Owens, W. E., C. H. Ray, J. L. Watts, and R. J. Yancey. 1997. Comparison of success of antibiotic therapy during lactation and results of antimicrobial susceptibility tests for bovine mastitis. J. Dairy Sci. 80:313-317. https://doi.org/10.3168/jds.S0022-0302(97)75940 $-\mathrm{X}$.

Pazoki, A., G. R. Ghorbani, S. Kargar, A. Sadeghi-Sefidmazgi, J. K. Drackley, and M. H. Ghaffari. 2017. Growth performance, nutrient digestibility, ruminal fermentation, and rumen development of calves during transition from liquid to solid feed: Effects of physical forms of starter feed and forage provision. Anim. Feed Sci. Technol. 243:173-185. https://doi.org/10.1016/j.anifeedsci 2017.06.004.

Pezhveh, N., G. R. Ghorbani, P. Rezamand, and M. Khorvash. 2014. Effects of different physical forms of wheat grain in corn-based starter on performance of young Holstein dairy calves. J. Dairy Sci. 97:6382-6390. https://doi.org/10.3168/jds.2013-7718. 
Porter, J. C., R. G. Warner, and A. F. Kertz. 2007. Effect of fiber level and physical form of starter on growth and development of dairy calves fed no forage. Prof. Anim. Sci. 23:395-400. https://doi.org/ 10.15232/S1080-7446(15)30994-3.

Senevirathne, N. D., J. L. Anderson, W. R. Gibbons, and J. A. Clapper. 2017. Growth performance of calves fed microbially enhanced soy protein in pelleted starters. J. Dairy Sci. 100:199-212. https:// doi.org/10.3168/jds.2016-11221.

Suarez-Mena, F. X., T. M. Hill, C. M. Jones, and A. J. Heinrichs. 2016. Effect of forage provision on feed intake in dairy calves. Prof. Anim. Sci. 32:383-388. https://doi.org/10.15232/pas.2016-01502.

Suarez-Mena, F. X., W. Hu, T. S. Dennis, T. M. Hill, and R. L. Schlotterbeck. 2017. $\beta$-Hydroxybutyrate (BHB) and glucose concentrations in the blood of dairy calves as influenced by age, vaccination stress, weaning, and starter intake including evaluation of BHB and glucose markers of starter intake. J. Dairy Sci. 100:2614-2624 https://doi.org/10.3168/jds.2016-12181.

Terré, M., E. Pedrals, A. Dalmau, and A. Bach. 2013. What do preweaned and weaned calves need in the diet: A high fiber content or a forage source? J. Dairy Sci. 96:5217-5225. https://doi.org/10 $.3168 /$ jds.2012-6304.

Thomas, D. B., and C. E. Hinks. 1982. The effect of changing the physical form of roughage on the performance of the earlyweaned calf. Anim. Prod. 35:375-384. https://doi.org/10.1017/ S0003356100001069.

Van Soest, P. J., J. B. Robertson, and B. A. Lewis. 1991. Methods for dietary fiber, neutral detergent fiber nonstarch polysaccharide in relation to animal nutrition. J. Dairy Sci. 74:3583-3597. https:// doi.org/10.3168/jds.S0022-0302(91)78551-2 (Doi). 